\title{
Anesthesia for elective bilateral sagittal slip osteotomy of the mandible and genioplasty in a young man with Klippel-Feil syndrome, Sprengel deformity, and mandibular prognathism
}

\author{
Rathna Paramaswamy \\ Department of Anaesthesiology, Saveetha Medical College and Hospital, Chennai, India
}

\begin{abstract}
Klippel-Feil syndrome is characterized by congenital fusion of two or more cervical vertebrae, a low hair line at the back of the head, restricted neck mobility, and other congenital anomalies. We report a 16-year-old young man with Klippel-Feil syndrome, Sprengel deformity of the right scapula, thoracic kyphoscoliosis, and mandibular prognathism with an anterior open bite. He was treated with orthodontic treatment and maxillofacial surgery. An anticipated difficult airway due to a short neck with restricted neck movements and extrinsic restrictive lung disease due to severe thoracic kyphoscoliosis increased his anesthesia risk. Due to his deviated nasal septum and contralateral inferior turbinate hypertrophy, we chose awake fiber optic orotracheal intubation followed by submental intubation. Considering the cervical vertebral fusion, he was carefully positioned during surgery to avoid potential spinal injury. He recovered well and his postoperative course was uneventful.
\end{abstract}

Keywords: Klippel-Feil Syndrome; Kyphoscoliosis; Mandibular Prognathism; Orthognathic Surgery; Sprengel Deformity; Submental.

This is an Open Access article distributed under the terms of the Creative Commons Attribution Non-Commercial License (http://creativecommons.org/licenses/by-nc/4.0/) which permits unrestricted non-commercial use, distribution, and reproduction in any medium, provided the original work is properly cited.

\section{INTRODUCTION}

Klippel-Feil syndrome (KFS) is a congenital musculoskeletal condition characterized by the fusion of two or more cervical vertebrae. Common symptoms include a short neck, low hair line at the back of the head, and restricted neck mobility. Its incidence is one in 40,00042,000 newborns worldwide with a slight predominance in females. KFS was initially reported in 1912 by Maurice Klippel and Andre Feil [1]. The treatment of symptomatic patients includes several surgical procedures involving a multidisciplinary team of a neurologist, orthopedic surgeon, pediatrician, nurse practitioner, physical therapist, neurologist, neurosurgeon, and maxillofacial surgeon. While some patients have no symptoms, a significant number have myelopathy and neuropathy, which significantly decrease quality of life [2]. KFS may be associated with Sprengel deformity, scoliosis, deafness, congenital heart disease, craniomaxillofacial deformities, pulmonary defects, facial nerve palsy, cleft palate, spina bifida, and genitourinary malformation [3,4]. Mutations in the GDF6, GDF3, and MEOX1 genes can cause KFS. The GDF6 gene is involved in proper bone formation, while the GDF3 gene is involved in bone development. The MEOX1 gene creates the homeobox protein MOX1, which regulates

Received: September 4, 2019 • Revised: September 20, 2019 • Accepted: September 24, 2019

Corresponding Author: Rathna Paramaswamy, MD, Professor, Department of Anaesthesiology, Saveetha Medical College and Hospital, Chennai 602105, India

Phone: +9940475385 E-mail: drrathna86@yahoo.co.in

Copyright@ 2019 Journal of Dental Anesthesia and Pain Medicine 


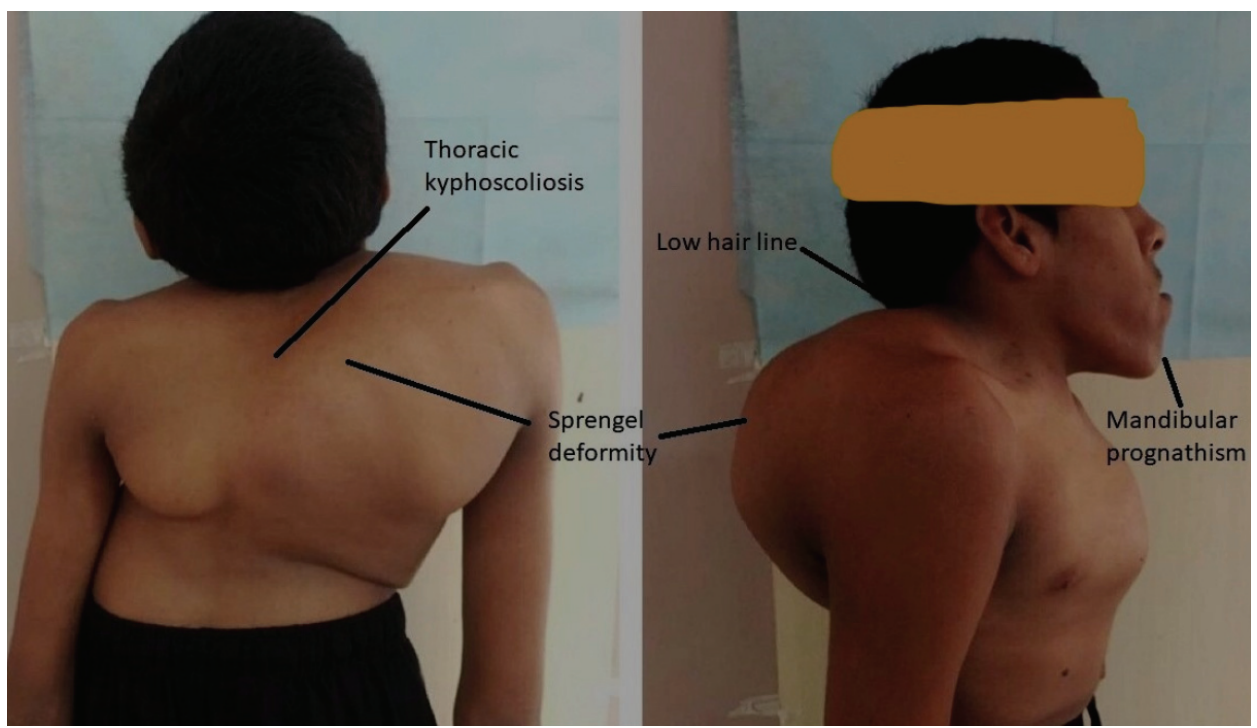

Fig. 1. Side and back view of the same patient showing a low hair line at the back of the neck, restricted neck movements, Sprengel deformity of the right scapula, thoracic scoliosis, and mandibular prognathism.

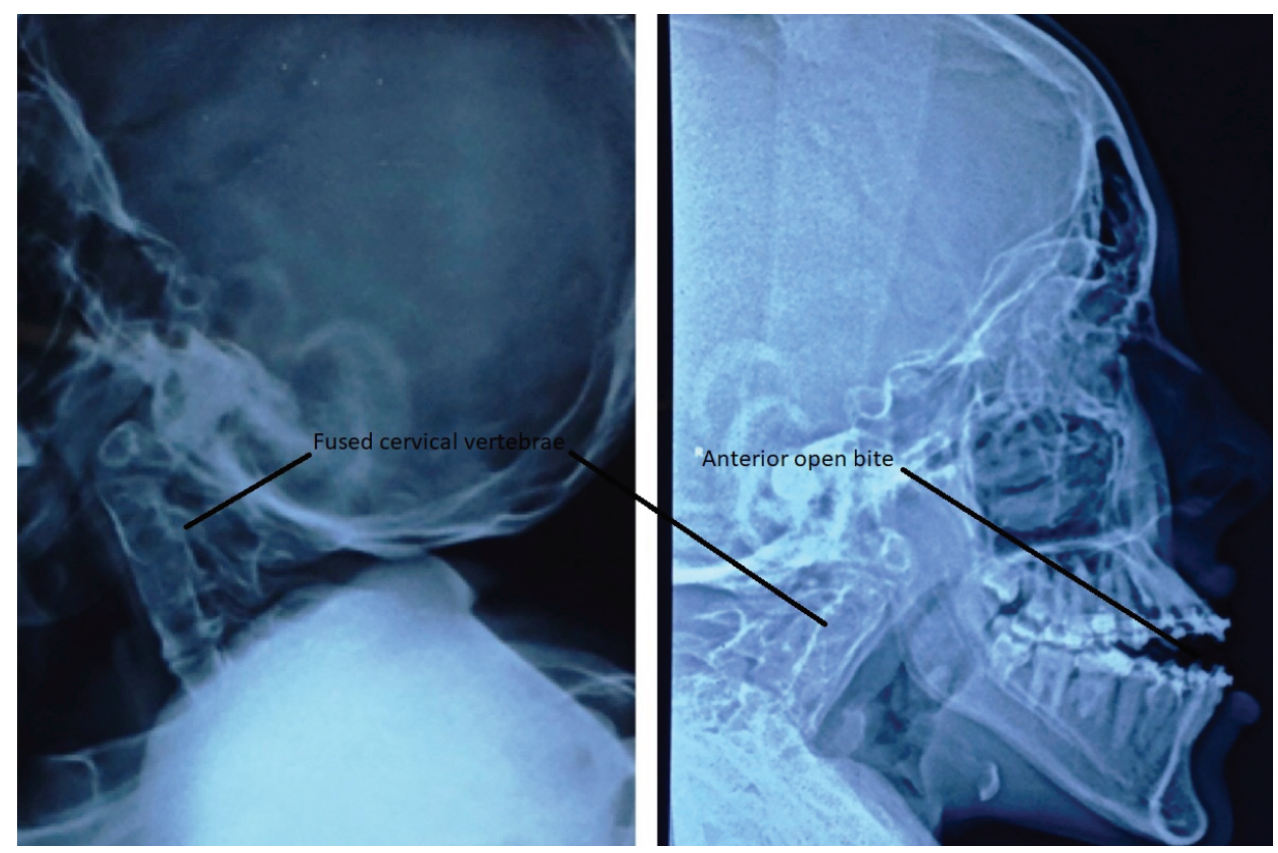

Fig. 2. Radiograph of neck showing fusion of the upper cervical vertebra and an extensive anterior open bite.

separation of the vertebrae. GDF6 and GDF3 gene abnormalities are inherited in an autosomal dominant pattern, while MEOX1 mutations are autosomal recessive [5]. Patients with KFS may be predisposed to congenital spinal stenosis; thus, a relatively low-impact injury may induce a significant neurological deficit [6]. This syndrome may occur simultaneously with Sprengel deformity, Duane syndrome, renal agenesis, fetal alcohol syndrome,
Goldenhar syndrome, Wildervanck syndrome, and other vascular and cardiac abnormalities [5-7]. Approximately $50 \%$ of patients with KFS will present with concurrent scoliosis [7-9]. Treatment is conservative and symptomatic only. In particular, with single or bilevel fusions below the third cervical vertebra are monitored and treated conservatively. 


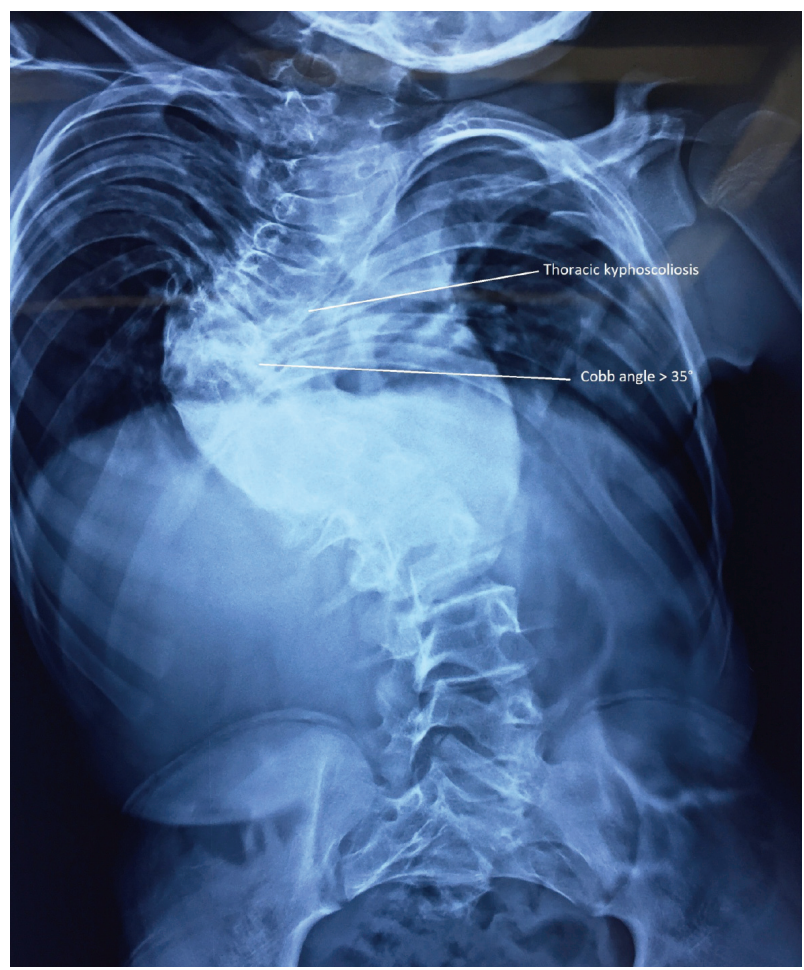

Fig. 3. Radiograph of the chest and abdomen showing thoracic kyphoscoliosis with Cobb angle $>35^{\circ}$.

\section{CASE REPORT}

A 16-year-old boy with KFS presented to our hospital's oral and maxillofacial surgery department with complaints of an inability to bite and chew food, lisping speech, and chronic jaw pain. He was born through cesarean section to nonconsanguineous parents and had no complications. His identical twin brother was absolutely normal. His past surgical history included two surgeries immediately after birth for anorectal agenesis and left orchidopexy at 3 years of age for undescended testis. On examination, he had grossly restricted neck movements, a low hair line at the back of the neck, malaligned teeth, marked mandibular prognathism, an extensive anterior open bite, and psychological disturbances. He had marked kyphoscoliosis of the thoracic spine and a right Sprengel deformity (Fig. 1).

An airway examination revealed Mallampati II with normal mouth opening and an inability to flex or extend the neck. Electrocardiography (ECG) showed normal

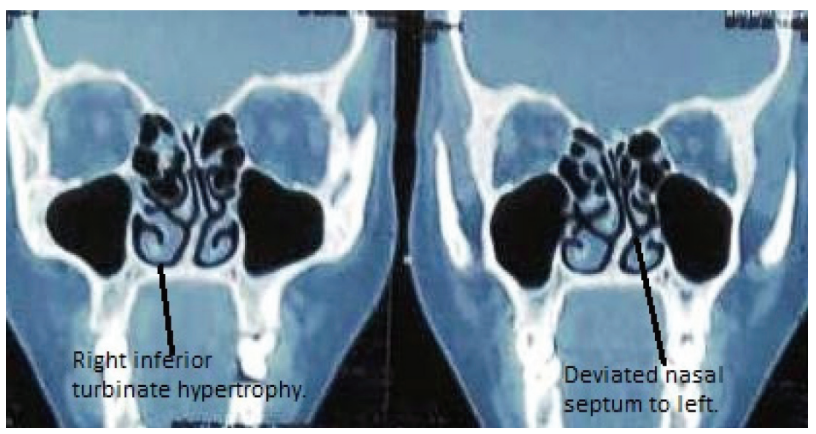

Fig. 4. Coronal unenhanced computed tomography scan of the paranasal sinuses showing a leftward deviated nasal septum with compensatory inferior turbinate hypertrophy on the right.

sinus rhythm and echocardiography findings were normal. Radiography of the neck revealed fusion of the upper six cervical vertebrae (Fig. 2). Chest radiography revealed thoracic kyphoscoliosis with Cobb angle $>35^{\circ}$ (Fig. 3). His exercise tolerance was good and he had a metabolic equivalent of task value of 8 . He had a weight of 50 $\mathrm{kg}$ and height of $150 \mathrm{~cm}$. His heart rate was 78 beats per minute and regular, blood pressure was $110 / 70$ $\mathrm{mmHg}$, and respiratory rate was 14 breaths per minute. Laboratory findings included: hemoglobin, $13 \mathrm{gm} \%$; platelets, 2.34 lakhs $/ \mathrm{mm}^{3}$; serum glucose, $99 \mathrm{mg} / \mathrm{dL}$; sodium, $142 \mathrm{mEq} / \mathrm{dL}$; potassium, $4.2 \mathrm{mEq} / \mathrm{dL}$; serum urea, $18.0 \mathrm{mg} / \mathrm{dL}$; and serum creatinine, $0.67 \mathrm{mg} / \mathrm{dL}$. A pulmonary function test revealed moderately restrictive lung disease. Nasal endoscopy revealed a leftward deviated nasal septum (DNS) and compensatory hypertrophy of the right inferior turbinate. Computed tomography of the paranasal sinuses confirmed those findings (Fig. 4).

After his parents provided informed consent, he underwent elective bilateral sagittal slip osteotomy of the mandible and a genioplasty. Oral ranitidine $150 \mathrm{mg}$ was administered the night before and the morning of the surgery, and he fasted for 6 hours prior to the surgery. To avoid a secondary cervical spine injury, he was self-positioned on the table with proper padding of the right elevated scapula and pressure points. His neck and head were properly padded and supported. His basal oxygen saturation was 98\%; an arterial blood gas analysis on room air revealed: $\mathrm{pH}, 7.35 ; \mathrm{PaCO}_{2}, 43 \mathrm{mmHg} ; \mathrm{PaO}_{2}$, 


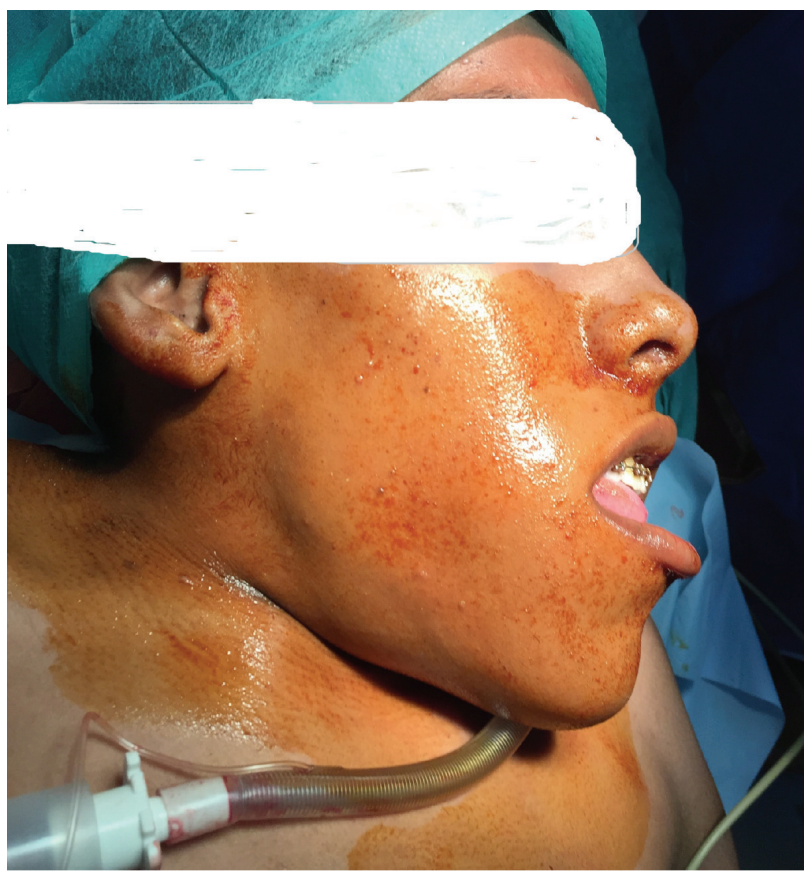

Fig. 5. Oral submental intubation.

$107 \mathrm{mmHg}$; bicarbonate, $24 \mathrm{mmol} / \mathrm{L}$; and arterial oxygen saturation, 99\%. An 18-gauge intravenous cannula was inserted on the dorsum of the left hand and a Ringers lactate infusion was started. Cephalexin $1 \mathrm{~g}$ was given intravenously.

The patient was connected to a multipara monitor displaying the ECG, noninvasive arterial pressure, invasive arterial pressure, end-tidal carbon dioxide $\left(\mathrm{ETCO}_{2}\right)$, pulse oximetry, and core temperature. ECG showed sinus rhythm with: heart rate, 89 beats/min; a normal axis; blood pressure, 120/60 $\mathrm{mmHg}$; and respiratory rate, 16 breaths/min. His right radial artery was cannulated and connected to a pressure transducer for blood gas sampling and continuous blood pressure monitoring. Considering his fairly reasonable metabolic equivalent of task value and hemodynamic parameters, an invasive central venous pressure line was considered unnecessary. Glycopyrrolate $0.2 \mathrm{mg}$ and ondansetron 4 mg were given intravenously.

Awake fiber optic bronchoscopy-guided orotracheal intubation was planned to secure the airway, followed by submental intubation to ensure unhindered surgical access (Fig. 5). A backup emergency surgical airway kit was kept in case of failure of the first method. The oropharynx was nebulized with 4\% lignocaine. The larynx and trachea were anesthetized by nebulization with lignocaine. Supplemental oxygen was administered via a nasal catheter. A 5.5-mm fiber optic bronchoscope was used and a $7.5-\mathrm{mm}$ cuffed reinforced endotracheal tube was slid up the full length of the shaft and gently secured to the beveled end of the bronchoscope. The tube was passed over the bronchoscope into the trachea just above the carina. Tube position was confirmed by capnographic trace and bilateral equal air entry. The cuff was inflated to seal the airway and the tube was securely fixed. Fentanyl $50 \mu \mathrm{g}(1 \mu \mathrm{g} / \mathrm{kg})$, propofol $100 \mathrm{mg}$, and atracurium $25 \mathrm{mg}$ were administered intravenously. Anesthesia was maintained using a mixture of $50 \%$ oxygen and $50 \%$ air and $1-1.5 \%$ isoflurane through a closed circuit with intermittent doses of atracurium. Intermittent positive pressure ventilation was instituted and $\mathrm{ETCO}_{2}$ was maintained at $35 \mathrm{mmHg}$.

The throat was packed with sterile tape gauze. Temporary draping of the mouth and chin were performed after standard skin preparation with $10 \%$ povidone-iodine solution. The surgeon made a $1.5-\mathrm{cm}$ incision in the left submental triangle after local infiltration of the skin with 2\% xylocaine with adrenaline. A Kelly's forceps was introduced through the skin incision and into the floor of the mouth by blunt dissection. The tube cuff was first introduced into the mouth after deflation and pulled inferiorly to pass through the intraoral tunnel and emerge through the submental incision. The proximal end of the reinforced tube was then disconnected from the circuit and connector and pulled extraorally through the submental incision. The connector was reattached and the circuit was re-established. Endotracheal tube position was checked again to ensure bilateral equal air entry. The cuff was inflated and the tube was sutured to the overlying skin and fixed with plaster tape to prevent accidental extubation. A fresh pharyngeal pack was then reinserted after removing the existing soaked throat pack. Intermittent positive pressure ventilation was instituted through a closed circuit with a circle absorber. 
Perioperatively, no significant changes in blood pressure or heart rate were noted (systolic pressure 95$110 \mathrm{mmHg}$, diastolic pressure $70-90 \mathrm{mmHg}$, and heart rate $80-110$ beats $/ \mathrm{min})$. The mean arterial pressure was maintained at 90-100 $\mathrm{mmHg}$. The surgery lasted for 3 hours and a total of $1200 \mathrm{~mL}$ of Ringers lactate was given. His arterial blood gas values during the perioperative period showed: $\mathrm{pH}$ 7.38; $\mathrm{PaO}_{2}, 158 \mathrm{mmHg}$; and $\mathrm{PaCO}_{2}$, $35 \mathrm{mmHg}$. Intravenous dexamethasone $8 \mathrm{mg}$ and ondansetron $4 \mathrm{mg}$ was given toward the end of the procedure.

At the end of the surgical procedure, the stay sutures around the tube were removed and the deflated cuff and tube were pulled in reverse order from the tunnel to the oral cavity. The oropharynx and nasopharynx were adequately suctioned and the throat pack was removed. The submental incision was sutured externally and a dressing was applied to the external wound. The intraoral incision was allowed for secondary healing and the residual neuromuscular blockade was reversed with neostigmine $2.5 \mathrm{mg}$ and glycopyrrolate $0.5 \mathrm{mg}$ until neuromuscular transmission recovered to a train of four ratio of 0.9 .

He was extubated awake with all protective airway reflexes and shifted to the postoperative recovery area. In this case, apnea during the circuit disconnection was 35 seconds and the total submental intubation was around 5 minutes. He was shifted to the high dependency unit for observation. The postoperative period was uneventful and he recovered well.

\section{DISCUSSION}

Securing the airway is a challenge in cases of complete fusion of the cervical spine and severe restriction of neck movements. Cervical vertebral fusion predisposes patients to the risk of neurological damage during positioning. In this case, anesthesia was successfully managed with a general anesthetic technique using awake fiber optic technique for orotracheal intubation followed by submental intubation. The nasotracheal route was the only suitable choice of intubation with unhindered surgical access that allowed dental occlusion. Due to nasal septum deviation and contralateral inferior turbinate hypertrophy, only the orotracheal route of securing the airway was possible. Due to restrictive lung disease and cervical spine fusion, he was not subjected to elective turbinate reduction and septoplasty. Hence, submental intubation was chosen as an alternative to conventional tracheostomy, which is more invasive and associated with complications such as hemorrhage, subcutaneous emphysema, pneumothorax, recurrent laryngeal nerve palsy, tracheomalacia, tracheal stenosis and erosions, respiratory tract infections, decannulation problems, scarring, and dysphagia.

Submental intubation is not completely free of complications. There is always a risk of arterial desaturation during the conversion from oral intubation to sub-mental intubation and vice versa. The pilot balloon can also be damaged during the tube transfer, and it may be difficult to pass the tube through the incision or reattaching the connector to the endotracheal tube. Complications like hemorrhage, accidental extubation, tube obstruction, and tube leakage are more difficult to manage in the submental route. Other complications include damage to the lingual nerve, salivary ducts, and orocutaneous fistula. He was followed up without complications and recovered well.

We highlight this case to discuss anesthesia management during orthognathic surgery for patients with KFS. Here, patient-related factors like an anticipated difficult airway, thoracic kyphoscoliosis, cervical vertebral fusion with a potential of serious neurological injuries and other system involvement require consideration. Elective postoperative care is very important in these patients considering the potential for postoperative airway obstruction due to laryngeal edema and soft tissue swelling.

\section{AUHOR ORCOIS}

Rathna Paramaswamy: https://orcid.org/0000-0002-0784-6952 
CONFLICTS OF INTEREST: The author has no financial interests to declare in relation to the content of this article.

\section{REFERENCES}

1. Pirino A, Sotgiu MA, Cosmi E, Montella A, Bandiera P. Association of Klippel-Feil syndrome, Dandy-Walker malformation, spina bifida: a case report. Radiol Case Rep 2019; 14: 415-8.

2. Rizvi A, Iwanaga J, Oskouian RJ, Loukas M, Tubbs RS. The course of the V2 segment of the vertebral arteries in Klippel-Feil syndrome: a case report. Cureus 2018; 10: e3038.

3. Hensinger RN, Lang JE, MacEwen GD. Klippel-Feil syndrome; a constellation of associated anomalies. J Bone Joint Surg Am 1974; 56: 1246-53.

4. Moore WB, Matthews TJ, Rabinowitz R. Genitourinary anomalies associated with Klippel-Feil syndrome. J Bone Joint Surg Am 1975; 57: 355-7.

5. Stelzer JW, Flores MA, Mohammad W, Esplin N, Mayl
JJ, Wasyliw C. Klippel-Feil syndrome with Sprengel deformity and extensive upper extremity deformity: a case report and literature review. Case Rep Orthop 2018; 2018: 5796730

6. Vaidyanathan S, Hughes PL, Soni BM, Singh G, Sett P. Klippel-Feil syndrome - the risk of cervical spinal cord injury: a case report. BMC Fam Pract 2002; 3: 6.

7. Kenna MA, Irace AL, Strychowsky JE, Kawai K, Barrett D, Manganella J, et al. Otolaryngologic manifestations of Klippel-Feil syndrome in children. JAMA Otolaryngol Head Neck Surg 2018; 144: 238-43.

8. Larson AR, Josephson KD, Pauli RM, et al. Klippel-Feil anomaly with Sprengel anomaly, omovertebral bone, thumb abnormalities, and flexion-crease changes: novel association or syndrome? Am J Med Genet 2001; 101: 158-62.

9. Samartzis D, Lubicky JP, Herman J, et al. Symptomatic cervical disc herniation in a pediatric Klippel-Feil patient: the risk of neural injury associated with extensive congenitally fused vertebrae and a hypermobile segment. Spine 2006; 31: E335-8. 